\title{
Influence of Grease on High-Pressure Gas Tightness by Metal-to-Metal Seals of Premium Threaded Connections
}

\author{
Keita Inose*, Masaaki Sugino and Kunio Goto \\ Steel Research Laboratories, Nippon Steel and Sumitomo Metal Corporation \\ 1-8, Fuso-cho, Amagasaki, Hyogo 660-0891, JAPAN \\ *Corresponding author: inose.53h.keita@jp.nssmc.com \\ ( Manuscript received 30 October 2015; accepted 25 January 2016; published 30 April 2016 ) \\ (Presented at the International Tribology Conference Tokyo 2015, 16-20 September, 2015 )
}

\begin{abstract}
A premium threaded connection for oil country tubular goods (OCTG) has a metal-to-metal seal portion to ensure its gas tightness under high pressure and high temperature. The metal surfaces are coated with grease and then integrated by rotary sliding. Despite several studies, the gas tightness mechanism of the metal-to-metal seal has not yet been clarified. In this study, as the first step to clarify the mechanism, we evaluated how grease affects the gas tightness by fundamental tests considering rotary sliding and grease degradation due to high temperature. Our results showed that grease is mandatory for the gas tightness of the metal-to-metal seals and the gas tightness is affected by both types of base oils and solid additives of grease. The seals coated with the grease composed of mineral oil had better gas tightness than those coated with that composed of plant oil, even after degradation due to high temperature. In addition, grease containing soft metal particles had better gas tightness than grease containing hard inorganic particles because the extended soft metal particles adhering to the rough parts of the seal surfaces reduced the size of the leakage paths.
\end{abstract}

Keywords: metal-to-metal seal, grease, gas tightness, rotary sliding, threaded connection, high pressure, high temperature

\section{Introduction}

In the oil and natural gas development industry, threaded connections are used to connect oil country tubular goods (OCTG), which are steel pipes that produce oil or natural gas from reservoirs (Fig. 1). These threaded connections have metal-to-metal seal portion(s) because they need to have not only high mechanical strength but also gas tightness under high pressure and high temperature conditions in the wells. Before the threaded connections are made up, the entire surfaces of the connections, including the metal-to-metal seal, are usually treated by phosphating or plating and coated by lubricant grease to prevent galling.

Typically, the metal-to-metal seal has a tapered shape and the diameter of the male seal surface is slightly larger than that of the female surface. With the progression of making up, the contact pressure on the seal gradually increases because of shrink fit, and finally, tight integration with high contact pressure over the seal circumference is formed [1]. Such tight integration of the seal achieves high-pressure gas tightness even at high temperatures.

In the field of the metal-to-metal seals of a premium threaded connection, several sealability studies have been conducted by fundamental laboratory tests [2-4]. Based on these test results, experimental criteria were proposed for designing their products. However, to date, no studies have considered a realistic situation such as rotary sliding during integrating and grease degradation due to high temperature. Therefore, the gas tightness

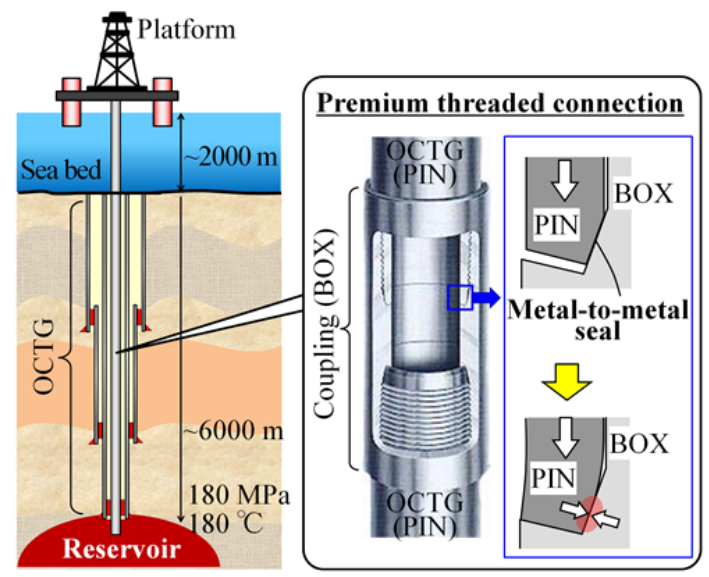

Fig. 1 Schematic of a well and a typical premium threaded connection 
mechanism of the metal-to-metal seals has not been clarified.

In the metal gasket field, some anterior studies have been conducted to investigate the sealing mechanisms. Nitta et al. [5] observed the real contact portions over the entire apparent contact area using a laser microscope. They determined the critical contact pressure at which the leakage flow in the radial direction ceases. Robbe-Valloire et al. [6] numerically investigated the real contact portions between a face-turned surface and a smooth surface. They showed that the percolation threshold depends on both crest and valley altitude distribution of the turned surface. Although their studies are very useful when considering the gas tightness mechanism of metal-to-metal seals, additional consideration is required for the application of metal-to-metal seals.

In this study, we conducted fundamental gas tightness tests that can simulate the contact conditions of metal-to-metal seals in premium threaded connections as the first step to clarify the gas tightness mechanism. In particular, the fundamental tests considering rotary sliding of the metal-to-metal seals during integration and grease degradation due to high temperature were conducted with two types of grease. We discussed how grease affects the gas tightness of the metal-to-metal seals based on the fundamental gas tightness test results, observation of tested seal surfaces, and so forth.

\section{Experimental procedure}

\subsection{Apparatus and specimen}

The testing apparatus was composed of an axial-rotational load flame, a heating chamber, and a high-pressure gas generator. In this study, mixed gas composed of nitrogen $(95 \%)$ and helium $(5 \%)$ was used.

Figure 2 shows a picture and a schematic of cross-sectional view of a pair of specimens made of L80 carbon steel for OCTG specified in the standards of the American Petroleum Institute 5CT [7], the nominal yield strength of which is $552 \mathrm{~N} / \mathrm{mm}^{2}$. Upper specimens were set to the moving shaft of the load flame, and lower specimens were cramped. The seal surface of the upper specimens was a torus and that of the lower specimens was flat. Consequently, a ring-shaped sealing contact portion having a width of about $2 \mathrm{~mm}$ and an average diameter of $12 \mathrm{~mm}$ appeared. These seal surfaces were machined by turning, and the seal surfaces of the upper specimens were treated by manganese phosphate. These surface conditions were almost the same as an actual premium threaded

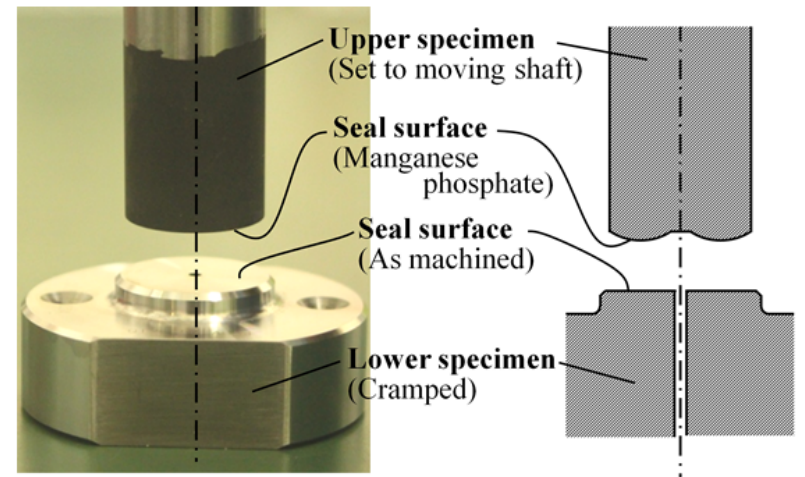

(a) Picture of specimens

(b) Schematic of crosssectional view

Fig. 2 A pair of specimens
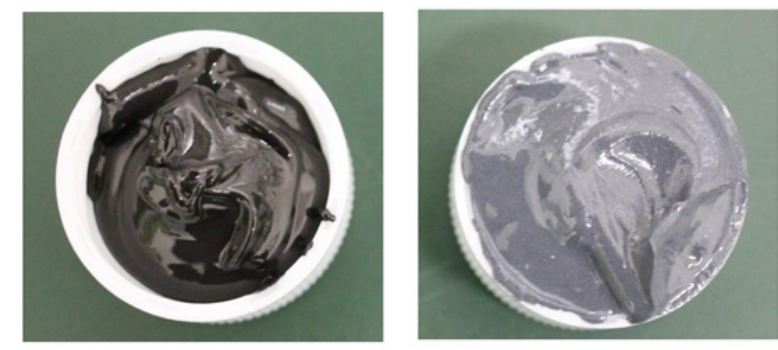

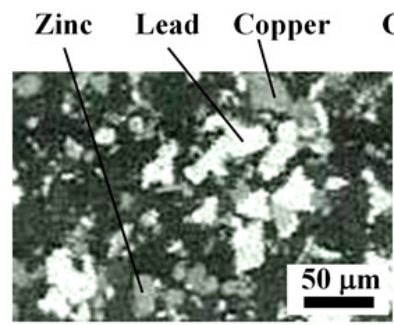

(a) Grease $\mathrm{A}$

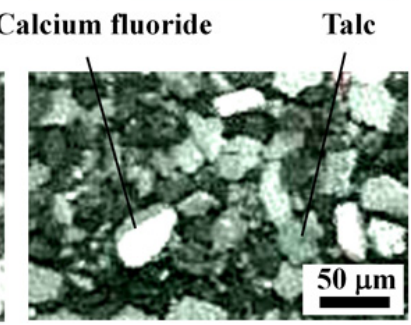

(b) Grease B
Fig. 3 Grease and its solid components

connection.

\subsection{Grease}

In this study, two types of compound grease for OCTG were used (Table 1). Figure 3 shows the grease and scanning electron microscope images of solid additives extracted from each grease. Grease $\mathrm{A}$ is a conventional lithium soap grease containing soft metal particles such as lead. Grease B is an environmentally friendly calcium soap grease containing hard inorganic particles such as calcium fluoride instead of soft metal particles.

\subsection{Test sequence}

Table 2 shows the test sequence of the three different fundamental gas tightness tests. These tests were

Table 1 Grease components

\begin{tabular}{c|c|c|c|c}
\hline Grease & Base oil & Thickener & Dropping point & Solid additive \\
\hline A & $\begin{array}{c}\text { Mineral } \\
\text { oil }\end{array}$ & Lithium soap & $287^{\circ} \mathrm{C}$ & $\begin{array}{c}\text { Lead, Zinc, Copper, Graphite, and } \\
\text { others }\end{array}$ \\
\hline B & Plant oil & Calcium soap & $297^{\circ} \mathrm{C}$ & $\begin{array}{c}\text { Calcium fluoride, Calcium carbonate, } \\
\text { Titanium dioxide, and others }\end{array}$ \\
\hline
\end{tabular}


Table 2 Test procedure of Test I, Test II, and Test III

\begin{tabular}{c|c|c|c}
\hline Test & $\begin{array}{c}\text { Rotary } \\
\text { sliding }\end{array}$ & $\begin{array}{c}\text { Baking } \\
\left(\mathbf{1 8 0} \mathbf{}^{\circ} \mathrm{C},\right. \\
\mathbf{1 2} \text { hours })\end{array}$ & $\begin{array}{c}\text { Applying } \\
\text { gas } \\
\text { pressure }\end{array}$ \\
\hline I & N/A & N/A & Applied \\
\hline II & Applied & N/A & Applied \\
\hline III & Applied & Applied & Applied \\
\hline
\end{tabular}

composed of the combination of rotary sliding, baking, and applying gas pressure. For instance, Fig. 4 shows the schematic of the test sequence in Test III.

Rotary sliding was conducted in accordance with ISO 13679 [8], which is the standard of the testing procedure for threaded connections. First, the seal surfaces were subjected to twice forward and backward rotations to simulate repetition of the make-up and break-out of the connections. Then, the seal surfaces were subjected to

\section{(A) Rotary sliding}

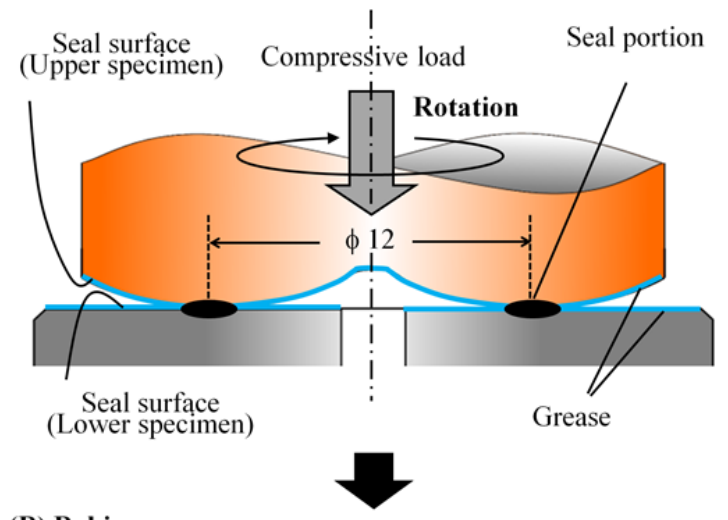

(B) Baking

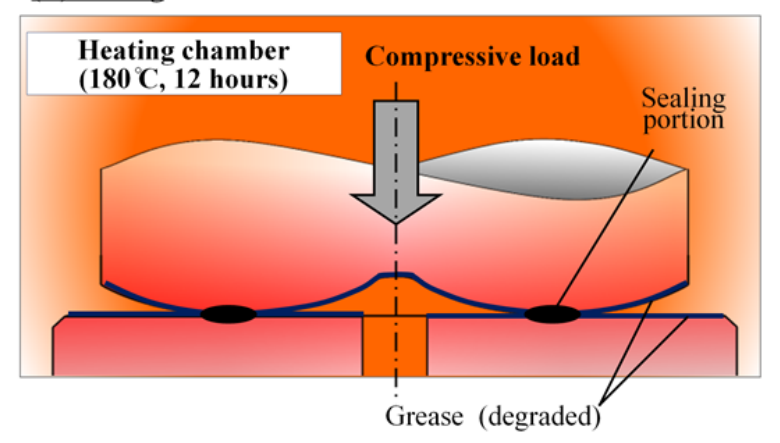

(C) Applying gas pressure

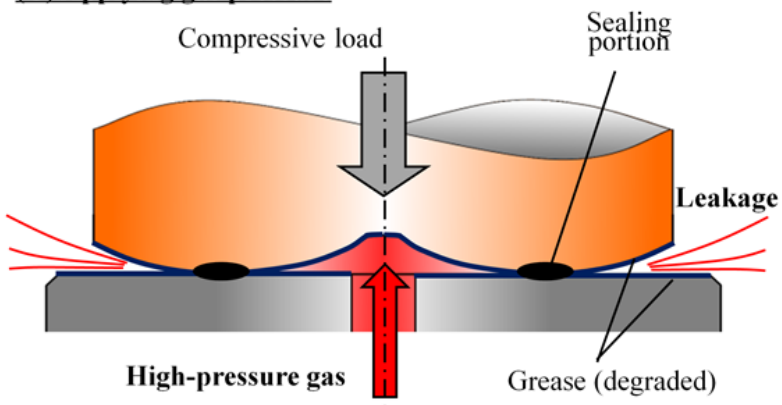

Fig. 4 Schematic of the test sequence at Test III forward rotation again to simulate final make-up, indicating that make-up of the connection was completed (Fig. 5). The maximum compressive load was $60 \mathrm{kN}$ with a sliding speed of $40 \mathrm{rpm}(25.2 \mathrm{~mm} / \mathrm{s})$. These sliding conditions were determined on the basis of the conditions of an actual premium threaded connection. During the forward rotations, the seal surface of the upper specimens was gradually pressed to that of the lower specimens to simulate the making-up. Then, during the backward rotations, the compressive load was gradually reduced to simulate the break-out. After backward rotations, the specimens were once detached to degrease and re-coated with fresh grease.

At baking, test specimens were heated at $180^{\circ} \mathrm{C}$ for 12 hours while maintaining a compressive load of 60 $\mathrm{kN}$. Then, the heating chamber was opened and test specimens were cooled down by air to room temperature. This heating condition was also determined

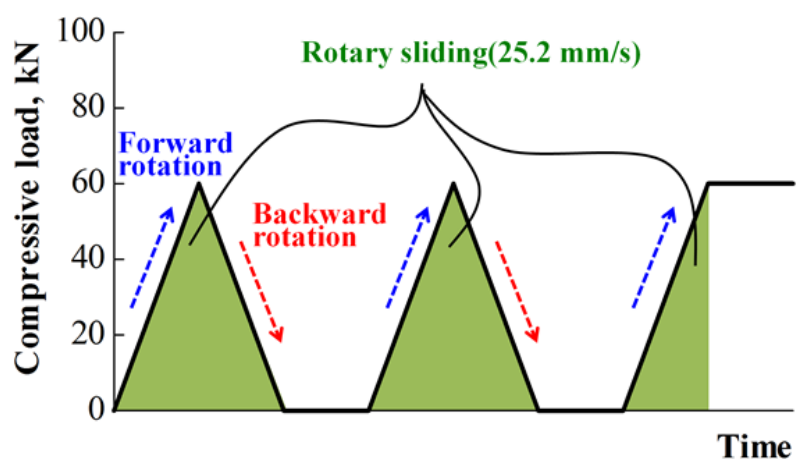

Fig. 5 Load diagram at rotary sliding

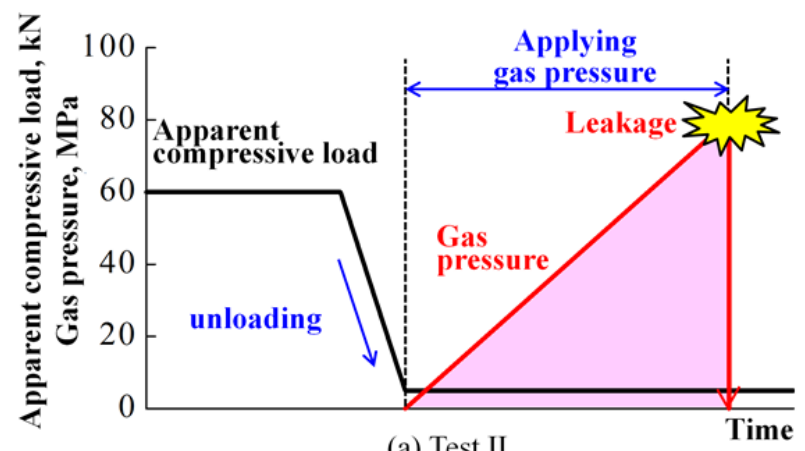

(a) Test II

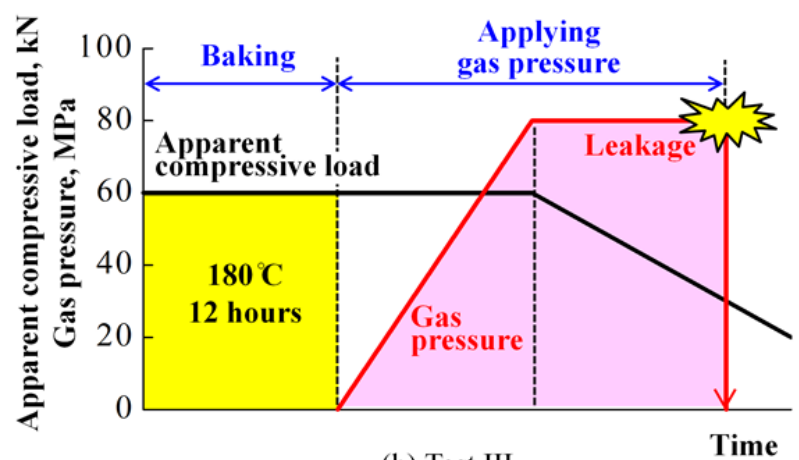

(b) Test III

Fig. 6 Load diagram of compressive load and gas pressure at gas tightness test 
according to ISO 13679.

On applying gas pressure, high-pressure gas was applied from inside of the ring-shaped sealing contact portion at room temperature. During the increase in the gas pressure, the apparent compressive load detected by the load cell installed below the lower specimen was controlled at a constant value. This means that the substantial compressive load applied to the sealing contact portion was decreased by the separating force induced by the gas pressure.

In Test I and Test II, gas pressure was increased while maintaining apparent compressive load until leakage occurred as shown in Fig. 6(a). In Test III, apparent compressive load was linearly decreased from $60 \mathrm{kN}$ at a rate of $0.025 \mathrm{kN} / \mathrm{s}$ while maintaining the gas pressure at $80 \mathrm{MPa}$ as shown in Fig. 6(b). Then, the applied gas pressure and apparent compressive load at the moment of leakage were recorded. In the case of rapid decompression of the leakage mode, the applied gas pressure just before leakage was defined as leakage pressure. In the case of a slow leak, the applied gas pressure at the moment the leakage rate of helium reached $5.1 \times 10^{-6} \mathrm{~Pa} \cdot \mathrm{m}^{3} / \mathrm{s}$ was defined as the leakage pressure.

\section{Results}

3.1. Gas tightness test without rotary sliding and baking (Test I)

Figure 7 shows the relationship between leakage pressure and apparent compressive load obtained from Test I. In Test I, a pair of specimens was repeatedly used for gas tightness tests at several apparent compressive loads: $2.5 \mathrm{kN}, 5 \mathrm{kN}, 10 \mathrm{kN}$, and so on.

For the nongreased specimens (NS), slow leak occurred as soon as gas was applied. In contrast, the leakage mode of all greased specimens was rapid decompression. For greased specimens, the leakage pressure was mostly increased in proportion to the apparent compressive load. The specimens coated with grease A (SA) had higher leakage pressure than those coated with grease B (SB). In addition, the leakage pressure of SB had larger dispersion in a high-pressure region than that of SA.

Figure 8 shows the microscopic images of seal surfaces after Test I. The red circles of $\phi 12 \mathrm{~mm}$ indicate the center of the seal contact portions. The seal surfaces of NS and SA were mostly undamaged. However, there were several dents on the lower seal surface and scratches on the upper seal surface of SB.

\subsection{Gas tightness test with rotary sliding (Test II)}

Figure 9 shows the leakage pressure obtained from Test II. For comparison, the leakage pressures of the specimens not subjected to rotary sliding, which were the results of Test I, are also shown in this graph. These gas tightness tests were conducted with an apparent compressive load of $5 \mathrm{kN}$. The leakage mode of all specimens was rapid decompression in these tests. Figure

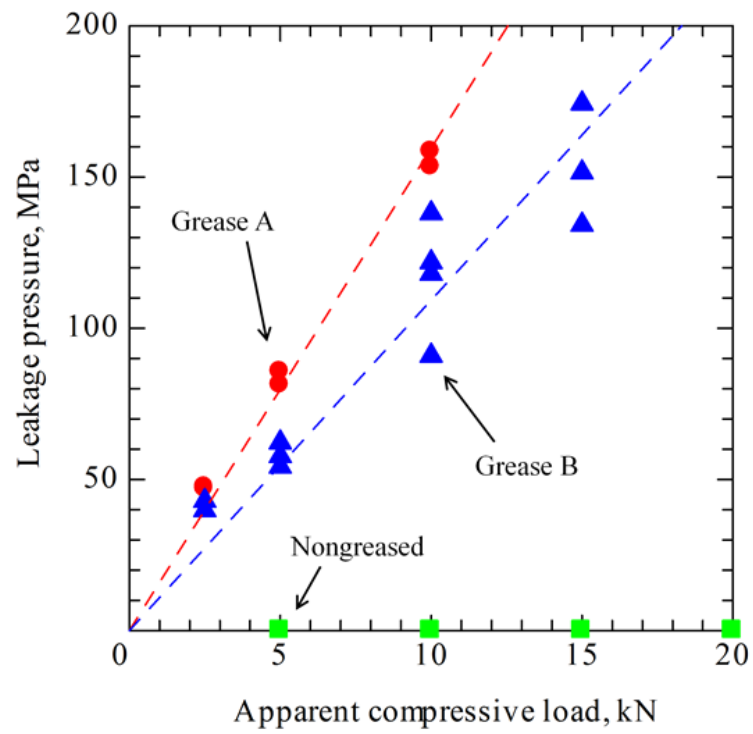

Fig. 7 Relationship leakage pressure with compressive load in Test I

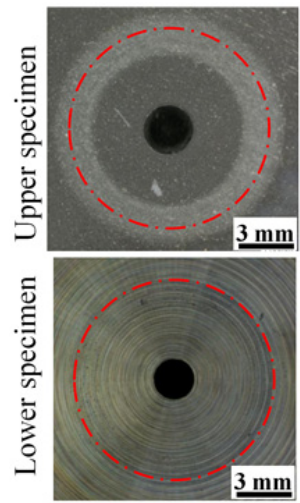

(a) Nongreased
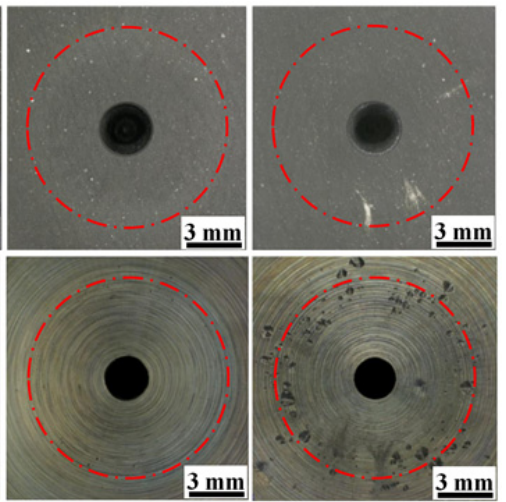

(b) Grease A

(c) Grease B
Fig. 8 Microscopic images of seal surfaces after Test I

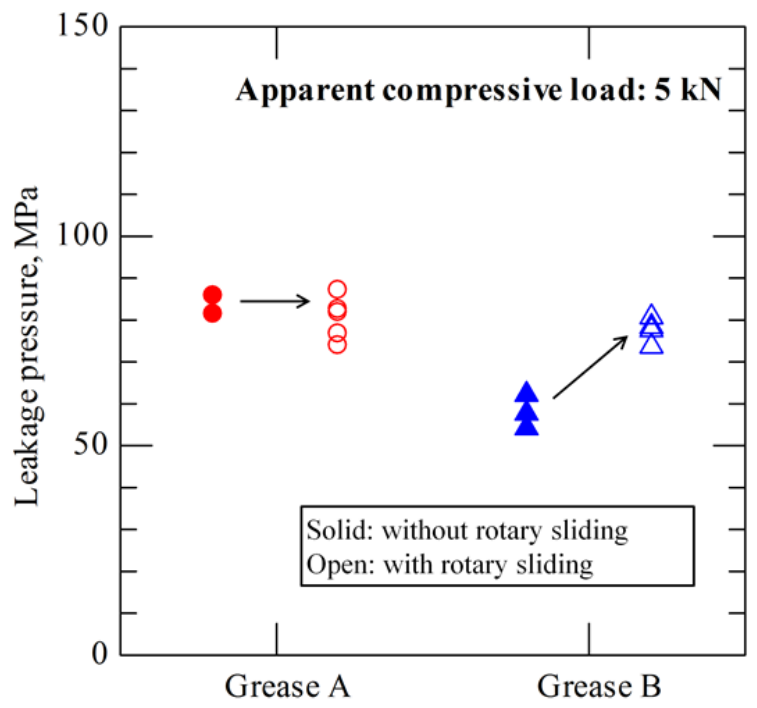

Fig. 9 The influence of rotary sliding on gas tightness (Test II) 
9 shows that the leakage pressure of SA was almost the same regardless of rotary sliding, whereas that of SB was improved by $18 \mathrm{MPa}$ after being subjected to rotary sliding.

Figures 10 and 11 show the microscopic images and surface profiles of seal surfaces after rotary sliding, respectively. For comparison, original surface profiles of seal surfaces were also shown in Fig. 11(a). The locations indicated by characters such as "A" in Fig. 10 correspond to those in Fig. 11. As shown in these figures, the seal surfaces of SA were mostly undamaged, although the color of the seal surfaces was changed by the adherence of the grease components. On the seal surfaces of SB, several concentric grooves and elevated edges were observed on the seal surface of the lower specimen.
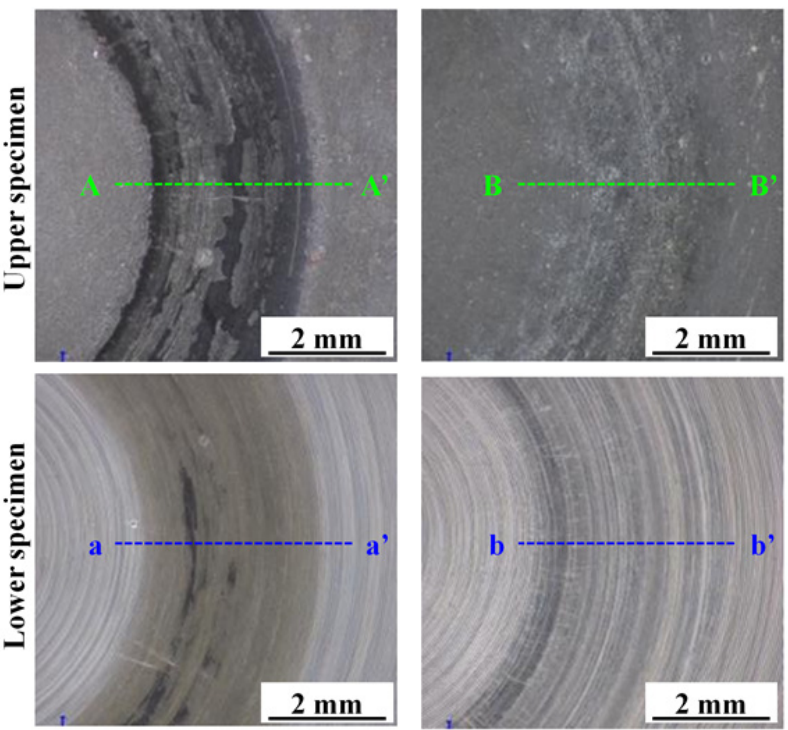

(a) Grease $\mathrm{A}$
Figure 12 shows the mapping images of energy dispersive X-ray analysis (EDX) and expected cross-sectional views of the seal portions of the upper specimens after being subjected to rotary sliding. At the seal portion of $\mathrm{SA}, \mathrm{Pb}$, which is a grease additive, was detected at the inverted portions of manganese phosphate. At the seal portion of SB, Fe, which is a base material, was detected at the inverted portions of manganese phosphate.

Figure 13 shows the contact pressure distributions of the original seals and those after being subjected to rotary sliding, measured at a compressive load of $2.5 \mathrm{kN}$ using pressure reacting films (Prescale, FUJIFILM). In this

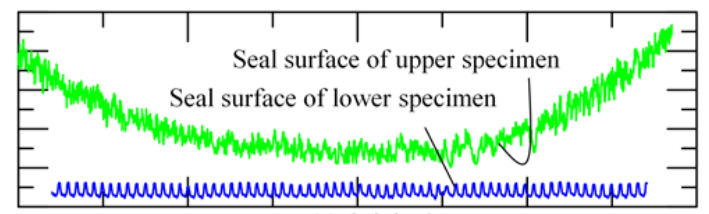
(a) Original

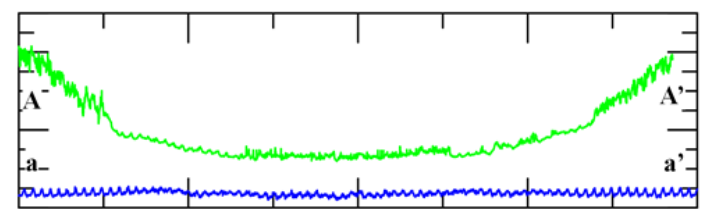

(b) After rotary sliding with Grease A

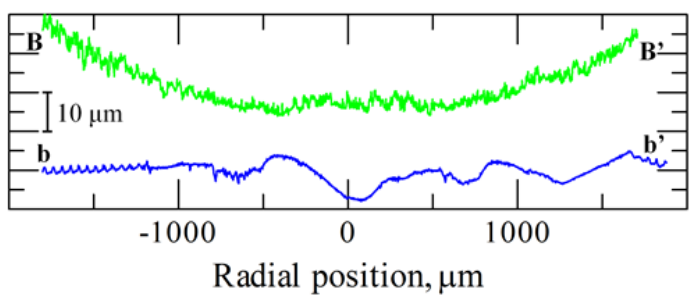

(c) After rotary sliding with Grease B

Fig. 11 Surface profiles of the seal measured using a laser microscope

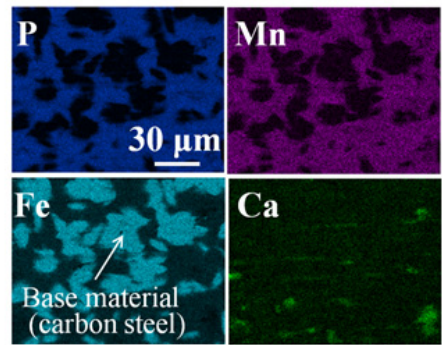

(b) Mapping images on SB

(a) Mapping images on SA
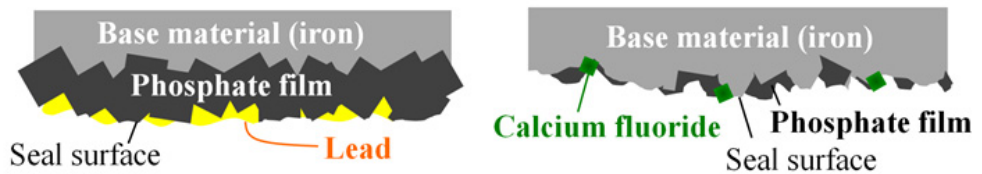

(c) Schematic of seal surface of SA

(d) Schematic of seal surface of SB

Fig. 12 Mapping images of EDX and schematic of cross-sectional view of the upper seal surfaces of the specimens subjected to rotary sliding 


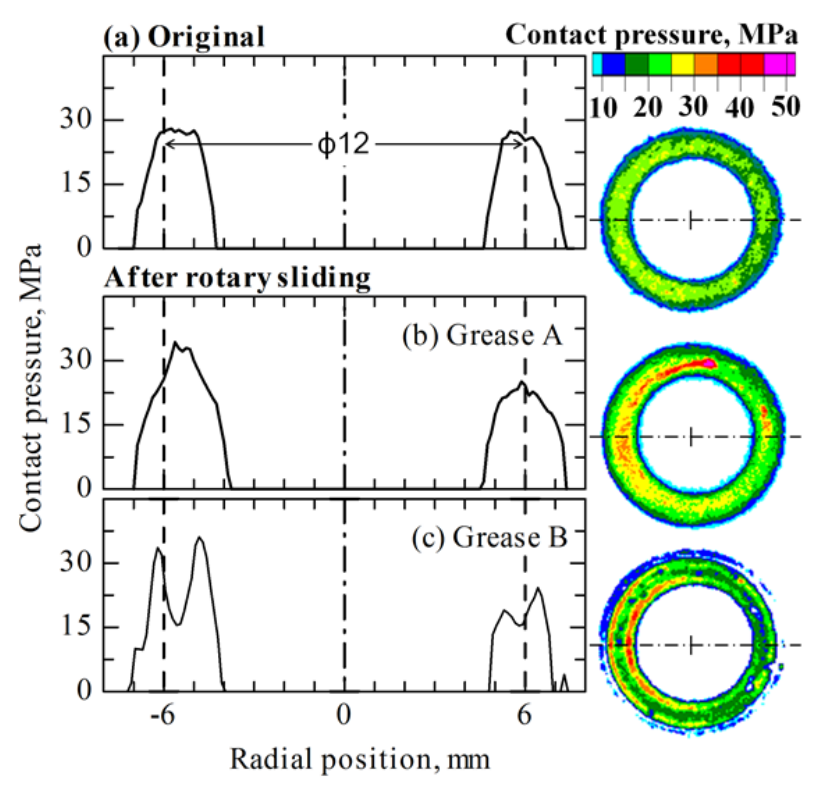

Fig. 13 Contact pressure distribution at the sealing portion

figure, the contact pressure distribution of SA was almost the same as original, whereas that of SB was changed to a concentric multi-peak distribution. However, these concentric contact portions were not contiguous in all circumferences, and there would be several gaps.

To compare the magnitude of the gaps on seal surfaces between SA and SB, additional tests were conducted. In these tests, specimens coated with grease were subjected to rotary sliding at first. Then, the specimens were once detached and degreased. Here, grease components adhering to the seal surfaces that were unable to be removed by a degreasing agent remained. After that, the specimens were compressed again with the apparent compressive load of $95 \mathrm{kN}$, and gas pressure was then increased. Figure 14 shows the relationship between leakage rates of helium and applied

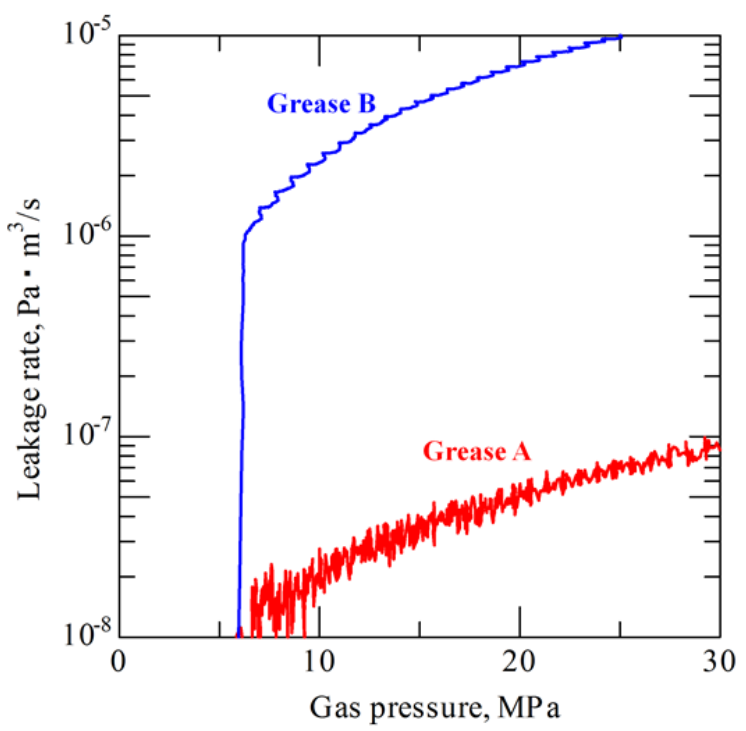

Fig. 14 Leakage rate of the degreased specimens

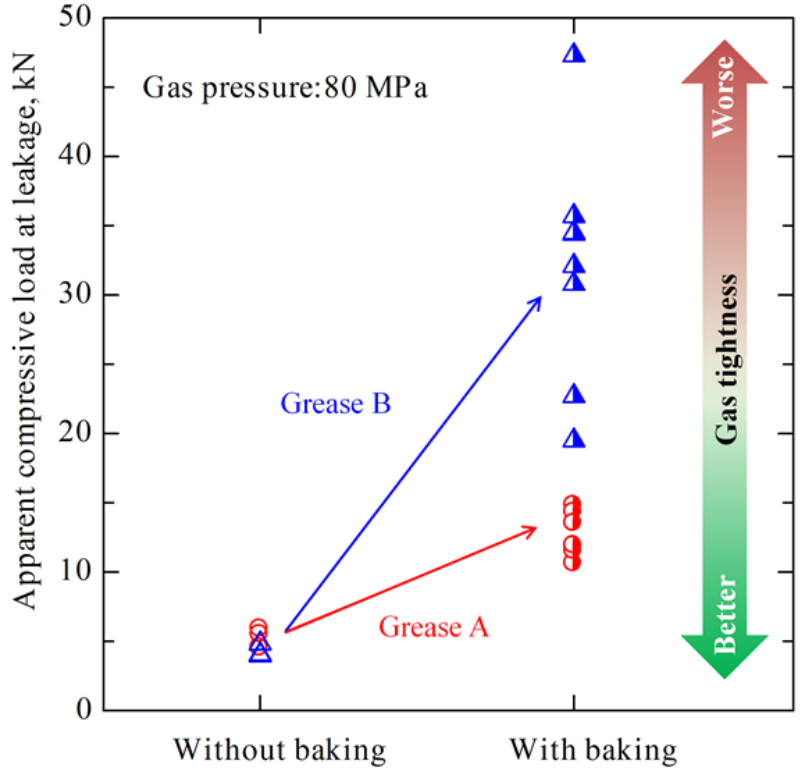

Fig. 15 Compressive load at leakage under gas pressure of $80 \mathrm{MPa}$ (Test III)

gas pressure. The specimen applied with grease A maintained a low leakage rate even after being degreased. In the specimen applied with grease $B$, the leakage rate rapidly increased as the gas pressure rose.

3.3. Gas tightness test with rotary sliding and baking (test III)

In Test III, apparent compressive load was decreased gradually from $60 \mathrm{kN}$ by maintaining a gas pressure of 80 $\mathrm{MPa}$. Figure 15 shows the apparent compressive loads at the leakage. The leakage mode of all specimens subjected to baking was slow leak, and the gas tightness of these specimens was dropped below that of the specimens not subjected to baking. However, SA still had

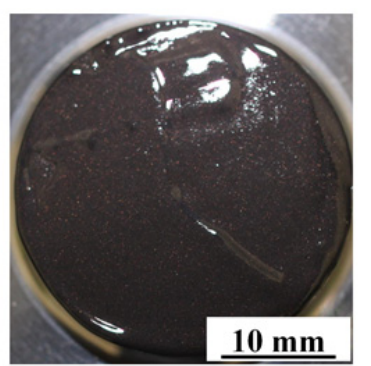

(a) Grease A (before baking)

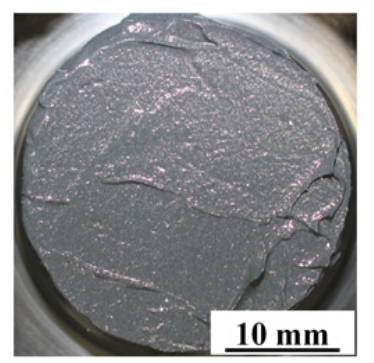

(c) Grease B (before baking)

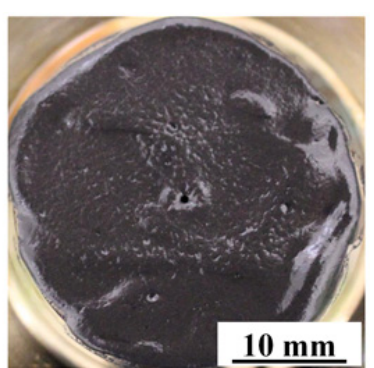

(b) Grease A (after baking)

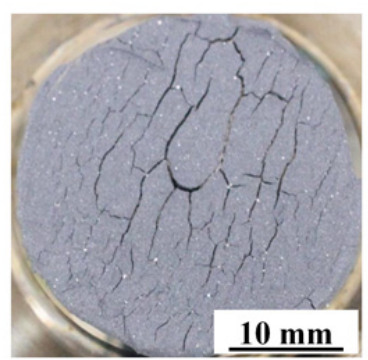

(d) Grease B (after baking)
Fig. 16 Grease appearances before and after baking 
better gas tightness than SB even after baking. In addition, the dispersion of the gas tightness of SA was smaller than that of SB.

To confirm how these greases change their state due to high temperature, grease A and grease B applied on the seal surfaces of lower specimens were baked in the heating chamber at $180^{\circ} \mathrm{C}$ for 12 hours. Consequently, both greases were degraded due to high temperature and had changes in appearances as shown in Fig. 16. Particularly, grease B lost large amount of base oil, while grease A was still oily.

\section{Discussion}

According to the result of Test I (Fig. 7), we can conclude that grease is mandatory for the gas tightness for the metal-to-metal seal as long as the conditions of Test I are met. In other words, the gas tightness is expected to be achieved by the grease filling microgaps between seal surfaces. This means that the leakage does not occur even in the presence of microgaps between seal surfaces unless the grease is pushed away from the seal surfaces by pressure load.

Test I also revealed that the type of grease affected the gas tightness. In particular, the type of solid additives had a significant impact on the gas tightness. SB after Test I had many dents on the lower seal surfaces as shown in Fig. 8(c). This means that the gap between the seal surfaces of SB would be larger than that between the seal surfaces of SA by difficult-to-dislodge inorganic particles between the seal surfaces. In addition, when substantial seal contact force was decreased by increasing applied gas pressure, percolation of the spaces around these particles was enabled to create larger leakage paths.

The hard inorganic particles contained in grease B were also expected to cause the dispersion of the leakage pressure in SB under high-pressure conditions in Test I. This dispersion was considered to be caused by the dents and radial scratches observed on the seal surfaces of SB as shown in Fig. 8(c). The scratches would be formed by hard inorganic particles spouting from between seal surfaces when the leakage occurred. As a pair of specimens was subjected to the gas tightness tests repeatedly in Test I, the difference in the number, length, depth, and so forth of these dents and scratches would affect the magnitude of the leakage paths, which results in the dispersion of the results of gas tightness tests. As the soft metal particles contained in grease A did not damage the seal surfaces as shown in Fig. 8(b), the dispersion of leakage pressure in SA would be small.

Next, we discuss the behavior of soft metal particles contained in grease A when the seal surfaces were subjected to rotary sliding. As shown in Figs. (10,11), SA subjected to rotary sliding had smoother seal surfaces than SB. The mapping images of EDX indicate that this smoothed surface was formed by the adherence of extended soft metal particles such as lead on the rough parts on the seal surfaces as shown in Fig. 12(c). In addition, the macroscopic contact pressure distribution on the seal surfaces did not change in comparison with that before being subjected to rotary sliding as shown in Fig. 13(b). This explains why the gas tightness of SA did not change regardless of rotary sliding. Moreover, this suggests that the seal surfaces were smoothed and leakage paths were narrowed by extended soft metal particles even without rotary sliding.

In contrast, hard inorganic particles contained in grease B induced the abrasive wear on the seal surfaces during rotary sliding, which resulted in the change in gas tightness. The upper seal surfaces of SB were locally abraded by rotary sliding so that $\mathrm{Fe}$, which is a base material, was exposed as shown in Fig. 12(d). In addition, several concentric grooves and their elevated edges were observed on the lower seal surfaces of SB as shown in Fig. 11(c). These elevated edges contributed to the formation of concentric high-contact-pressure portions as shown in Fig. 13(c). As these portions would shut the leakage paths off from percolating in the radial direction, the gas tightness of SB subjected to rotary sliding was improved in comparison with that of SB not subjected to rotary sliding.

Finally, the results of Test III indicate the gas tightness was dropped by the grease degradation due to high temperature, regardless of the type of grease as shown in Fig. 15. The grease degradation due to high temperature is caused by the base oil degradation, thickener degradation, and so forth. In this study, we expected that the base oil degradation had a major impact on the drop of the gas tightness after baking because grease A and grease B had almost the same dropping points that indicate the thermal resistance of the thickener as shown in Table 1.

The base oil degradation due to high temperature, which means a decrease in the amount and increase in viscosity for example, would result in the decrease in grease volume and hardening of grease. When the grease volume is decreased, a vacant space is formed between the seal surfaces. Moreover, the hardening of grease would make it difficult for the grease to flow into the newly formed spaces between the seal surfaces because of the decrease in substantial seal contact force. Therefore, percolation of the leakage paths would be facilitated, and the gas tightness was considered to be dropped after grease degradation due to high temperature.

The gas tightness differed significantly between SA and SB after grease degradation due to high temperature. As shown in Table 1, because grease A was composed of mineral oil that has a higher heat resistance than the plant oil of which grease B was composed, grease A would have a smaller decrease in volume and less hardening due to high temperature than grease B. In addition, because SA had smaller gaps between seal 
surfaces than SB, judging from the difference in the leakage rate shown in Fig. 14, percolation of the leakage paths on SA would be more difficult than that on SB even if the vacant space was newly generated by the decrease in grease volume. Therefore, SA would have better gas tightness than SB even after grease degradation due to high temperature. On the other hand, because the gas tightness of SB after grease degradation due to high temperature was strongly affected by the size or location of the grooves formed by abrasive wear, the results of Test III for SB would be widely dispersed.

\section{Conclusions}

Three different fundamental gas tightness tests in terms of rotary sliding during integration and grease degradation due to high temperature were conducted with two types of grease. The effect of grease on the gas tightness of metal-to-metal seals was investigated, and the following conclusions were obtained:

(1) The nongreased specimens had no gas tightness. This means that grease is mandatory for the gas tightness for the metal-to-metal seals.

(2) Specimens coated with grease A containing soft metal particles had better gas tightness than those coated with grease B containing hard inorganic particles in the tests without rotary sliding because the gap between the seal surfaces of SB was larger than that between the seal surfaces of SA by difficult-to-dislodge hard inorganic particles between the seal surfaces.

(3) The gas tightness of SA did not change regardless of rotary sliding because the seal surfaces were smoothed and leakage paths were narrowed by extended soft metal particles.

(4) The gas tightness of SB was improved after being subjected to rotary sliding because of the formation of concentric high-contact-pressure portions, which shut the leakage paths off from percolating in the radial direction.

(5) The gas tightness was dropped by grease degradation due to high temperature, regardless of the type of applied grease. Among the grease degradation due to high temperature, the decrease in grease volume and hardening of grease induced by base oil degradation would mainly affect the gas tightness.

(6) The gap between the seal surfaces of SA was smaller than that between the seal surfaces of SB. In addition, the base oil of grease A had a higher heat resistance than that of grease B. For these two reasons, the gas tightness of SA would be superior to that of SB even after grease degradation due to high temperature.

\section{References}

[1] Sugino, M., Yamaguchi, S., Ugai, S., Hamamoto, T. and Nakamura, K., "VAM ${ }^{\circledR} 21$, an Innovative High-Performance Premium Threaded Connection for OCTG," Nippon Steel \& Sumitomo Metal Technical Report No. 107 February 2015.

[2] Matsuki, N., Morita, Y. and Kawashima, H., "Evaluation of Premium Connection Design Conditions," ASME ETCE Drilling and Production Symp. Feb., 1985, 73-81.

[3] Tsuru, E., Nishi, S., Kohyama, F., Ogasawara M. and Mimaki, T., "Simulation Study of Bearing Pressure for Metal Seal of Tubular Connection : Metal-to-Metal Seal Mechanism for Premium Connection I," The Iron and Steel Institute of Japan, 72, 12, 1986, S1138 (in Japanese).

[4] Murtagian, G. R., Fanelli, V., Villasante, J. A., Johnson, D. H. and Ernst, H. A., "Sealability of Stationary Metal-to-Metal Seals," Journal of Tribology, 126, 2004, 591.

[5] Nitta, I., Matsuzaki, Y., Tsukiyama, Y., Horita, M. and Sakamoto, S., "Thorough Observation of Real Contact Area of Copper Gaskets Using a Laser Microscope With a Wide Field of View," Journal of Tribology, 135, 2013, 041103-1.

[6] Robbe-Valloire, F. and Prat, M., "A Model for Face-Turned Surface Microgeometry Application to the Analysis of Metallic Static Seals," Wear, 264, 2008, 980-989.

[7] API Specification 5CT: Specification for Casing and Tubing. 8h Edition. American Petroleum Institute, 2005.07.

[8] ISO 13679: 2002: Petroleum and Natural Gas Industries -Procedures for Testing Casing and Tubing Connections. 2002. 